\section{穴 Heighten Science P U B L I C A T I O N S Corporation ISSN 2574-0350}

\title{
Thermal Stress Analysis of a Continuous Rigid Frame Bridge
}

\author{
Shiwei Ge ${ }^{1}$, Yafei Xü ${ }^{2 *}$, Xiao Zhou ${ }^{3}$ and Shangyu Peng ${ }^{4}$ \\ ${ }^{1}$ Henan Provincial Communications Planning \& Design Institute Co., Ltd, Henan Zhengzhou, \\ China \\ ${ }^{2}$ Henan traffic institute of science and technology co., Ltd, Henan Zhengzhou, China \\ ${ }^{3}$ School of Civil Engineering, Chongqing Jiaotong University, Chongqing, China \\ ${ }^{4}$ Chongqing Audit Bureau, China
}

*Address for Correspondence: Yafei Xu, Henan Traffic Institute of Science and Technology co., Ltd, Henan Zhengzhou 450006, China; Email: 13253529091@163.com

Submitted: 01 March 2017

Approved: 23 March 2017

Published: 24 March 2017

Copyright: @ $2017 \mathrm{Ge} \mathrm{S}$, et al. This is an open access article distributed under the Creative Commons Attribution License, which permits unrestricted use, distribution, and reproduction in any medium, provided the original work is properly cited.

\section{ABSTRACT}

Thermal stress of a continuous rigid frame bridge, based on the temperature gradient in Chinese bridge gauge, using a finite element analysis (FEA) method was investigated. First of all, the temperature effect of the whole bridge was analyzed, and the correlation of the improved amplitude of temperature gradient and temperature effect were studied. It was found that there was a linear relationship with temperature stress and improved temperature. And then, the temperature effect of zero block was analyzed and the details of box girder temperature stress distribution investigated by utilizing the FEA method. It was concluded that temperature stress mainly distributed in the body surface; under the condition of the improvement of temperature field, the center temperature stress of zero block was improved about $60 \%$ and the end temperature stress of zero block was improved about $75 \%$.

\section{INTRODUCTION}

Nowadays, many long-span bridges have been built [1,2]. Because the box section has strong torsional and flexural capacity, and it can work well under the condition of bending shear stress, therefore it has been widely used in large span bridge. For highway Bridges, suffering the long-term temperature changes in the weather, the sun's radiation and cold current lowering temperature, each point temperature of both inside and outside surface on the box girder are changing every moment [3]. Concrete belongs to the material that has very poor thermal conductive performance; under the sunshine and the influence of inner and outer casing section, there is often a big temperature difference between inside and outside of the box section, temperature stress has significant difference, leading to large temperature difference stress. Tensile strength of concrete is weak, and body temperature stress without full consideration, so it will not appear tensile stress prestressed concrete box girder, causes a lot of serious cracks in some local regions and reduces structural bearing capacity and the service life.

Literature [4], introduced the general features of the intensity of solar radiation and solar radiation absorption coefficient of the concrete structure temperature effect, analyzed the influence of the solar radiation absorption coefficient on the simply supported box girder strength and stiffness, finally putted forward some measures for decreasing the temperature effect; Literature [5], through the experiment of five pieces of $\mathrm{h}$ beam, studied the effects of differing coefficients of thermal expansion, variations in service temperature, elevated curing temperatures and effects of 
temperature gradient at hardening, and test results was verified by calculation, Finally it was concluded that the use of high curing temperatures during fabrication affects the level of prestress because the strand length is fixed during the heating, the coefficients of thermal expansion of steel and concrete differ, and the concrete temperature distribution may not be uniform, these effects combined to reduce the calculated prestressing stress from the original design values at release by $3 \%$ to $7 \%$, to reduce the initial camber by $26 \%$ to $40 \%$, and to increase the bottom tension stress in service by $12 \%$ to $27 \%$, the main effect of applying the standard service temperature profiles to the bridge was to increase the bottom stress by $60 \%$ of the allowable tension stress; Literature [6] a continuous steel structure as the background, using the least squares fitting the measured temperature, and then through the finite element software analysis the horizontal temperature gradient temperature effect of web, concluded that to transverse positive temperature gradient of web can only consider unilateral web and negative temperature gradient should be considered on both sides, and to positive temperature gradient, tensile stress value-added of the top of floor is bigger; Literature [7] analyzed the impact of continuous beam temperature stress, it was concluded that temperature had a greater influence on the stress of the bridge, bigger temperature difference of inside and outside can case tensile stress, needed to control the temperature difference of inside and outside; Literature [8] according to the analysis of field test data, with three line mode temperature gradient model, proposes the corresponding curve type, and comparative analysis to the influence of this model and several typical specification temperature gradient of the domestic and foreign on the internal force and deformation of the structure of the bridge; Literature [9] through thermal imager to observe concrete box girder temperature field under the sunshine, and used ANSYS software to analyze the effect of temperature load, under the action of sunlight, the vertical temperature gradient field of the box beam was the curve form, temperature gradient load existed in box girder web plate and bottom plate.

Through the above analysis, at present domestic and foreign scholars on the temperature gradient of the enclosure structure research mainly as follows: comparative analysis to the structure temperature effect of mode calculation of temperature gradient in every country standard; through field observation of the box, fitting a temperature field of a particular bridge or with the measured data to improve the temperature gradient, and then analyzed temperature effect. But the existing researches embarked less from how to reduce the temperature difference of the inside and outside of box girder, and to improve the temperature effect of box girder. Internal and external temperature difference is reduced, the temperature stresses have been amplitude decreases, and thus the temperature crack problem will be solved. Therefore this paper, taking a continuous rigid frame bridge in Yunnan province as an example, based on the temperature gradients within the Chinese bridge gauge, First analyzed the temperature effect of the whole bridge, studied the correlations of the improved amplitude of temperature gradient and temperature effect, and then analyzed the detail temperature effect of zero block, finally discussed the detail temperature stress distribution rule of the box girde.

\section{MECHANISM OF TEMPERATURE}

\section{The mechanism of temperature effect}

Temperature field of the prestressed concrete box structure is $3 \mathrm{~d}$ heat conduction problem, the any one internal temperature point of structure is the function of $3 \mathrm{~d}$ coordinate and time. For continuous girder Bridges and continuous rigid frame bridge, their lengths are bigger than the vertical dimension and lateral dimension, are long and narrow structure. So along the lateral dimension of the bridge, the temperature changes can be considered as consistent, it can be considered as a bridge lateral or vertical heat conduction problem for $3 \mathrm{~d}$ heat conduction problem. Such a three dimensional 
temperature field can be simplified into a horizontal or vertical temperature gradient form of Bridges. The temperature of the enclosure structure gradient generally is nonlinear, but box girder section deformation comply with flat section assumption, and then make the section temperature difference strain between the fibers of the longitudinal direction constrained, therefore, on the section produced self-balanced longitudinal restraint stress, namely Self-stress. Temperature mechanism as shown in figure $1[10]$.

\section{Box cooling mechanism}

Solar sleeve is based on two types of mechanism to reduce surface temperature of concrete box structure, the one is using thermal insulation material to avoid direct sunlight; the other is that Solar energy drives the breeze machine to reduce the surface temperature of structures directly.

\section{PROJECT SUMMARY}

Relying on the project of a super-large continuous rigid frame bridge in the highway of Zhao tong to Hui ze, Main bridge upper structure is $102+190+102 \mathrm{~m}$ prestressed concrete continuous rigid frame box girder. beam height of Zero block root is $11.7 \mathrm{~m}$, mid-span is $4.2 \mathrm{~m}$; Roof thickness of zero block is $50 \mathrm{~cm}$ and at no. 1 (1') block changes to $28 \mathrm{~cm}$, thick of the rest are $28 \mathrm{~cm}$; from mid-span to roots, Plate thickness changes from $32 \mathrm{~cm}$ to $130 \mathrm{~cm}$. webs are divided into five sections from mid-span to roots, adopting three thickness: $90 \mathrm{~cm}, 70 \mathrm{~cm}$ and $50 \mathrm{~cm}$, the height of box girder changes by 1.8 parabola.

\section{TEMPERATURE EFFECT ANALYSES}

\section{The establishment of the whole finite model}

Simulated analysis of the whole temperature effect is proceeded by finite element software Midas Civil to, Using beam element model, a total of 254 units of the whole bridge, 259 nodes, Material is C55 concrete; Modulus of elasticity: $3.55 \times 10^{4}$; Design value of concrete tensile strength: $1.89 \mathrm{MPa}$. Poisson's ratio: 0.2 , the coefficient of linear expansion: alpha $=1 \times 10^{5}$. Using the function of section temperature of Midas to input temperature load. The whole bridge model is shown in figure 2 .

\section{The establishment of zero block detail limited model}

The detail temperature effect analysis of zero block of box is simulated by using the finite element software Midas FEA. For more accurate simulation of temperature gradient in the function of bridge specifications, refine folded linear temperature gradient function, and refine box girder roof relative to height as with temperature gradient function, Using cell temperature to simulate temperature gradient Function,

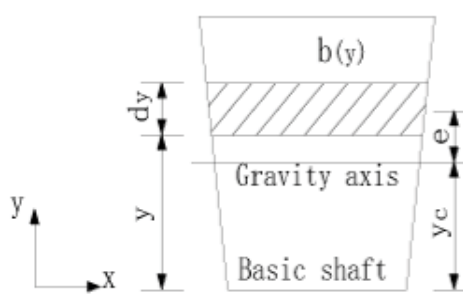

a) Section

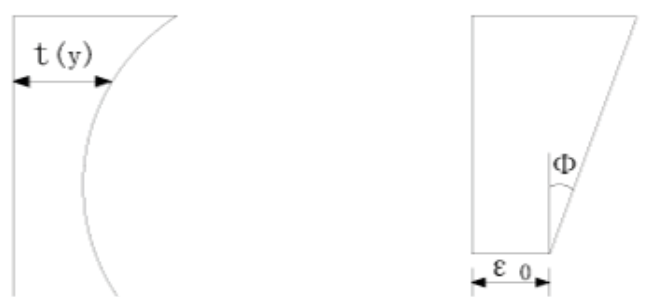

b) Temperature gradient c) Plane deformation d) Autogenous strain

Figure 1: The mechanism of temperature effect. Figure a) shows position of the sectional characteristic, the shaded part is the micro units of the studied temperature effects, Figure b) shows the mode of temperature gradient, Figure c) for the assumption of plane deformation section, Figure d) shows the temperature strain superposition of the vertical and horizontal bridge. 
the height of roof refined $10 \mathrm{~cm}$, Refine motioned as shown in figures 3 and 4 . According to the symmetry take zero block as the research object in general.

\section{Temperature gradient model}

Taking the "highway bridge design general specification" (JTG D62-2015) as the foundation, made the temperature gradient model of specification improved in different degree (Table 1) [11].

\section{THE CORRELATION ANALYSIS OF THE KEY SECTION TEMPERATURE STRESS AND TEMPERATURE GRADIENT}

Take the whole bridge as the research object, through the improvement of basic temperature gradient, study on the relationship of the temperature improved range and the box temperature effect. Compressive stress symbol is negative, the tension is positive.

It can be seen from figures 5-8, with the improvement of temperature gradient, temperature tension and compression stress of the key section significantly
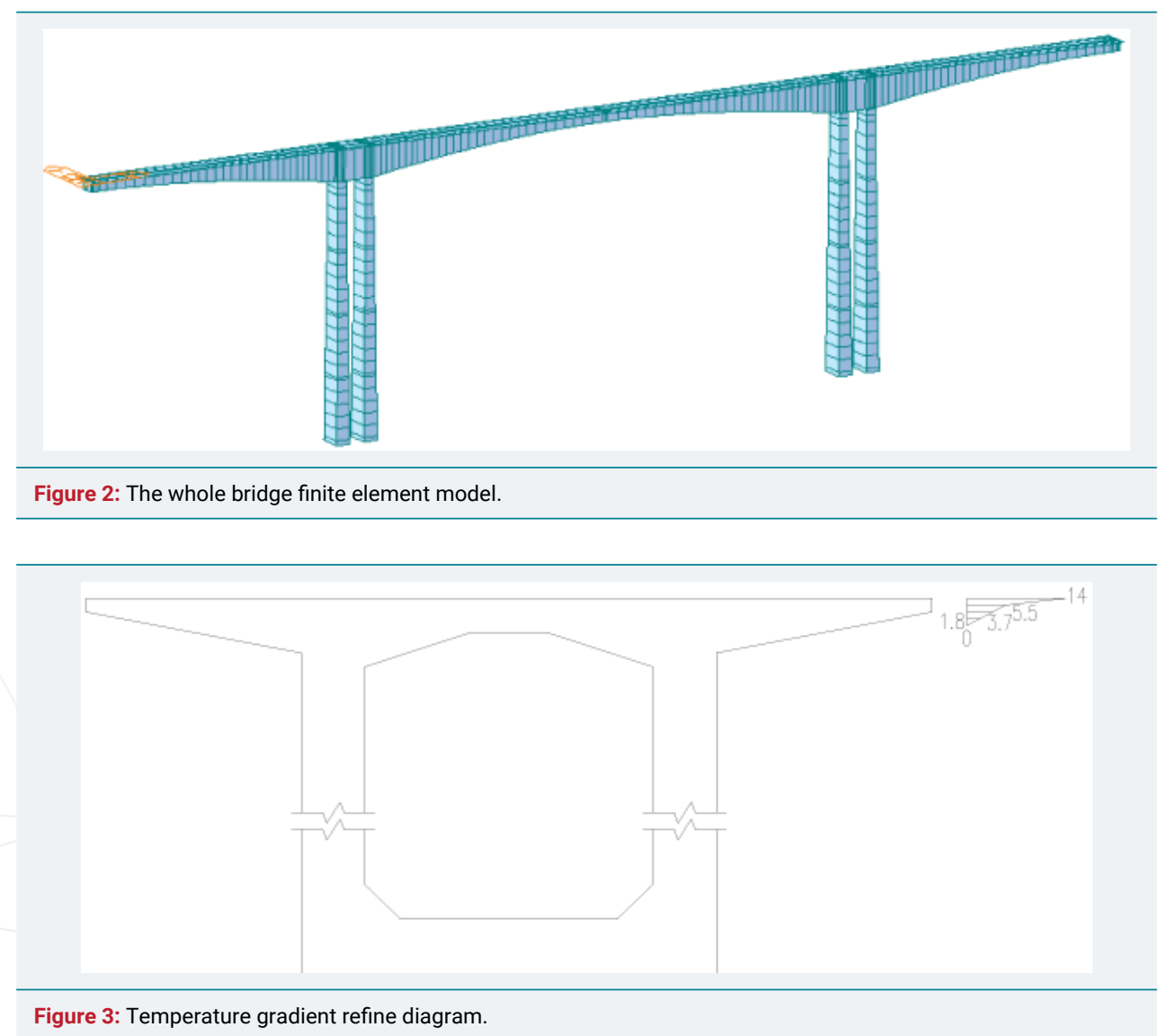

Table 1: Working condition of temperature gradient.

\begin{tabular}{|c|c|c|c|c|c|c|}
\hline \multirow{2}{*}{$\begin{array}{l}\text { Working } \\
\text { condition }\end{array}$} & \multicolumn{2}{|c|}{$\begin{array}{l}\text { Temperature } \\
\text { rise }\end{array}$} & \multicolumn{2}{|c|}{ cooling } & \multirow{2}{*}{$\begin{array}{l}\text { the biggest improvement } \\
\text { of positive temperature } \\
\text { difference } \\
\left({ }^{\circ} \mathrm{C}\right)\end{array}$} & \multirow{2}{*}{$\begin{array}{l}\text { the biggest improvement } \\
\text { of negative temperature } \\
\text { difference } \\
\left({ }^{\circ} \mathrm{C}\right)\end{array}$} \\
\hline & $\mathrm{T} 1\left({ }^{\circ} \mathrm{C}\right)$ & $\mathrm{T} 2\left({ }^{\circ} \mathrm{C}\right)$ & $\begin{array}{c}\mathrm{T} 1 \\
\left({ }^{\circ} \mathrm{C}\right)\end{array}$ & $\begin{array}{c}\mathrm{T} 2 \\
\left({ }^{\circ} \mathrm{C}\right)\end{array}$ & & \\
\hline 1 & 14 & 5.5 & -7 & -2.75 & - & - \\
\hline 2 & 13 & 5 & -6.5 & -2.5 & 1 & 0.5 \\
\hline 3 & 12 & 4.5 & -6 & -2.25 & 2 & 1 \\
\hline 4 & 10 & 4 & -5 & -2 & 4 & 2 \\
\hline 5 & 8 & 3 & -4 & -1.5 & 6 & 3 \\
\hline 6 & 5 & 2 & -2.5 & -1 & 9 & 4.5 \\
\hline
\end{tabular}


reduced about 60\%; Upper and lower margin temperature stress of the box is linear relationship with improved temperature range. Temperature rises, superior margin are all compressive stress, lower margin are tensile stress, temperature drop is on the other hand; the relationship of temperature stress of key section is: $1 / 2$ main span= root $>1 / 4$ side span $>1 / 4$ midspan $>$ side span.

\section{ZERO BLOCK TEMPERATURE STRESS DETAIL ANALYSIS}

Start with temperature gradient mode of China bridge gauge, under the condition of temperature rising and dropping, explore the regularities of distribution of transverse thermal stress and longitudinal temperature stress and principal tension-compression stress of zero block; Study on the temperature stress distribution along the box girder roof and improved range of temperature stress under different temperature improved.

\section{The temperature stress analysis under cooling and rise}

Figures 9-14 shows that temperature stress distribution of box girder roof is similar under the condition of rise and cooling, just stress in different sizes and symbol instead. Temperature rise, the box girder roof is compressive stress, cooling condition, is tensile stress.

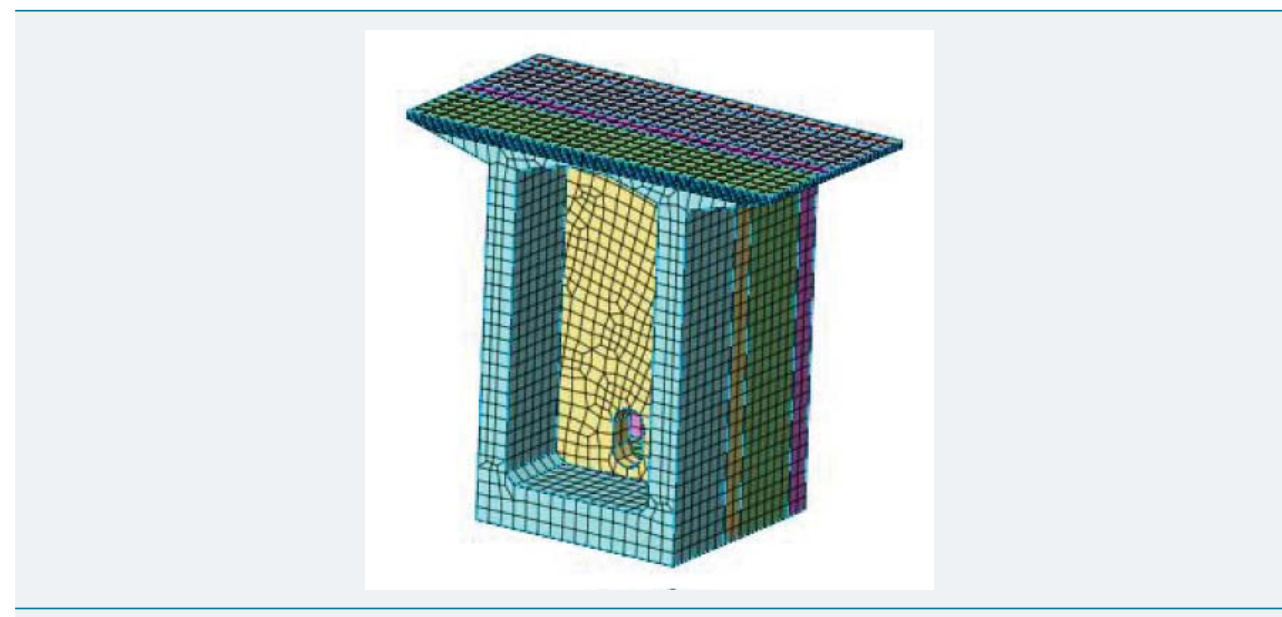

Figure 4: Zero block finite element model. Blue and cyan unit are box girder of zero block, yellow and pink unit are diaphragm plate of zero block.

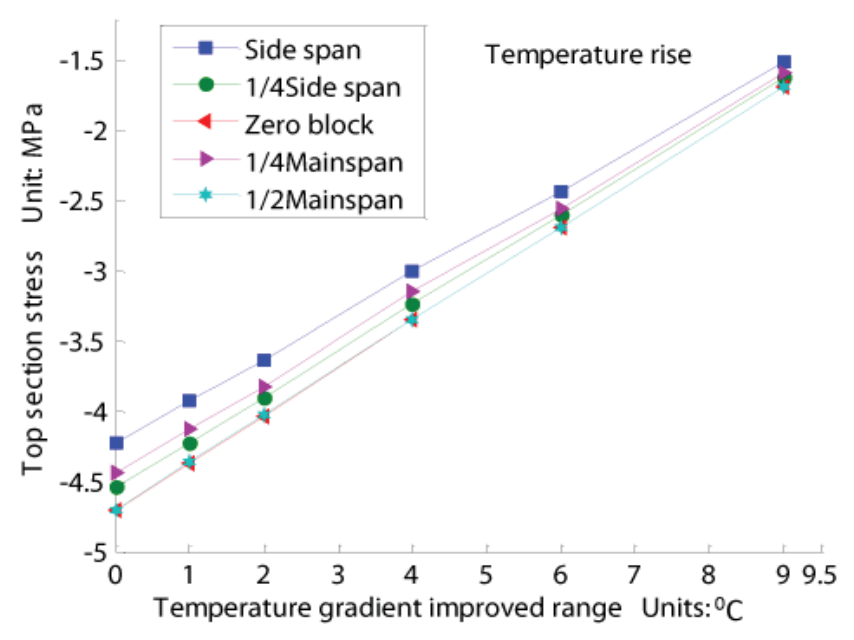

Figure 5: Superior margin stress of Temperature rise. 

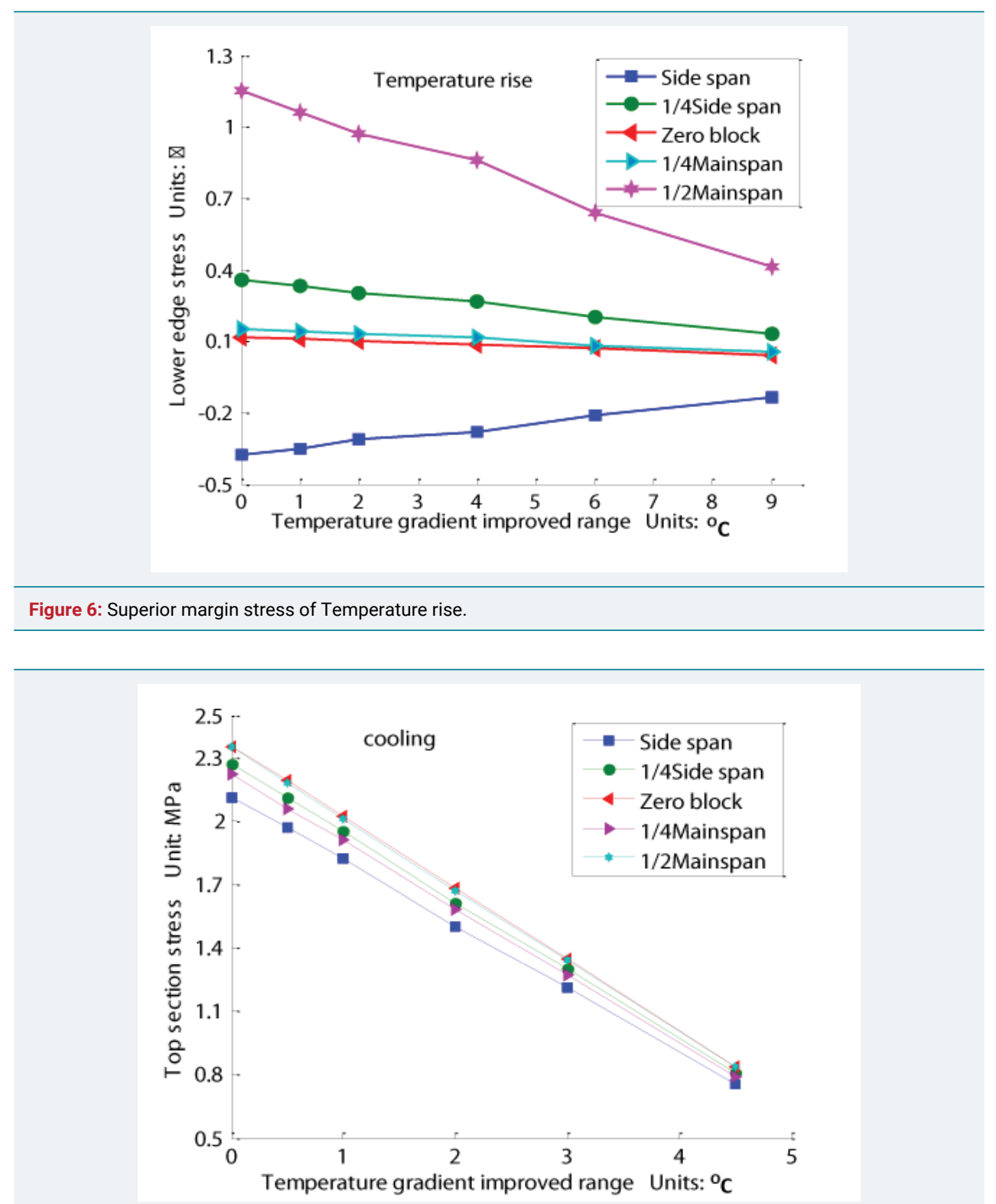

Figure 7: Superior margin stress of Temperature drop.

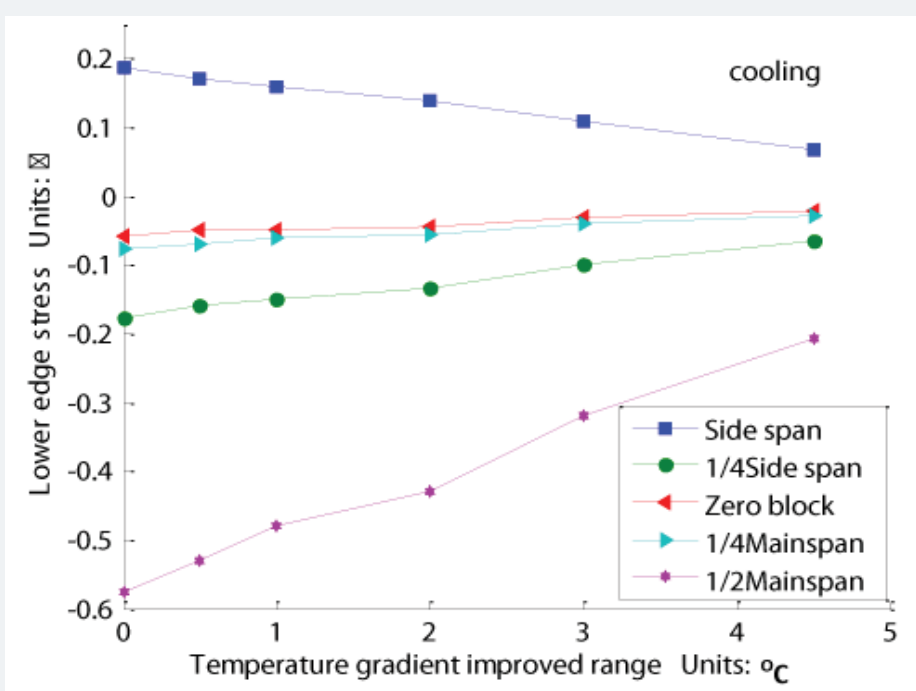

Figure 8: Lower margin stress of Temperature drop. 


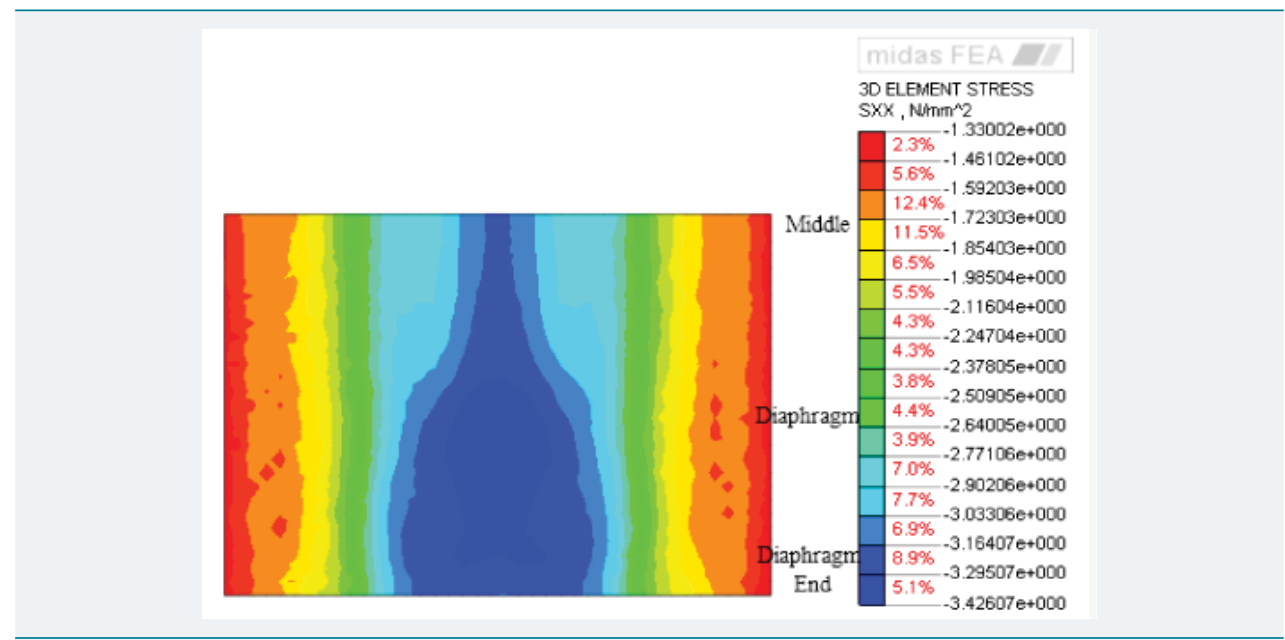

Figure 9: Transverse stress of roof under rise.

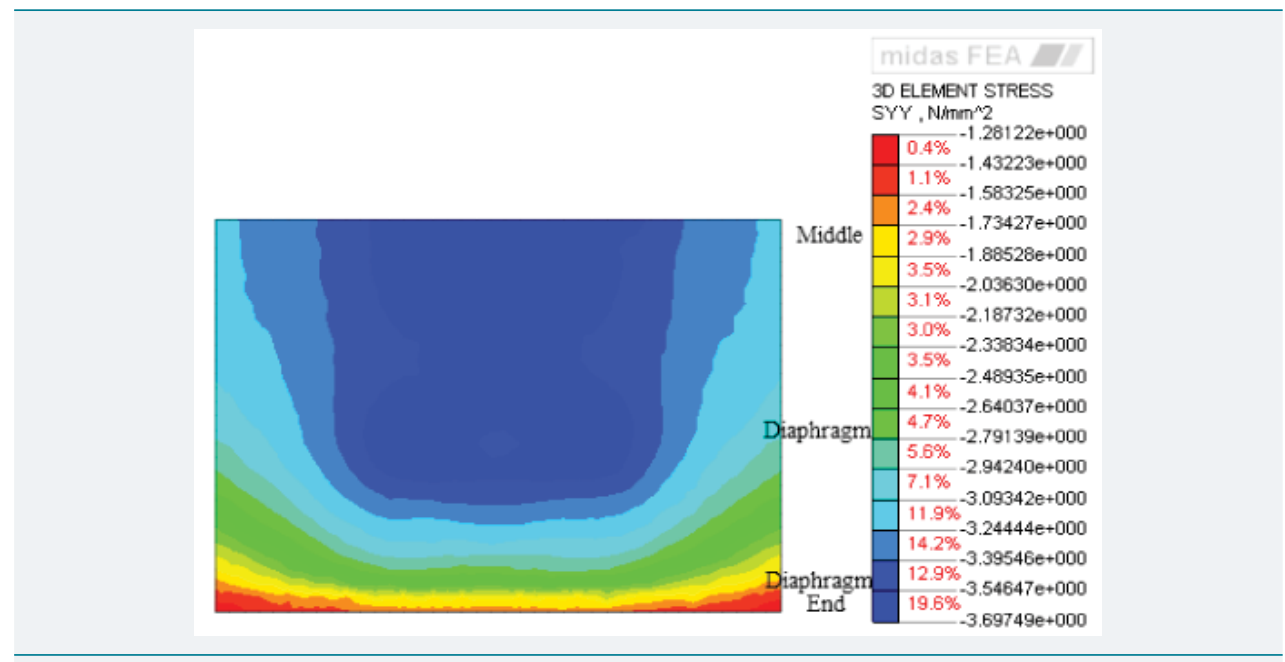

Figure 10: Longitudinal stress of roof under rise.

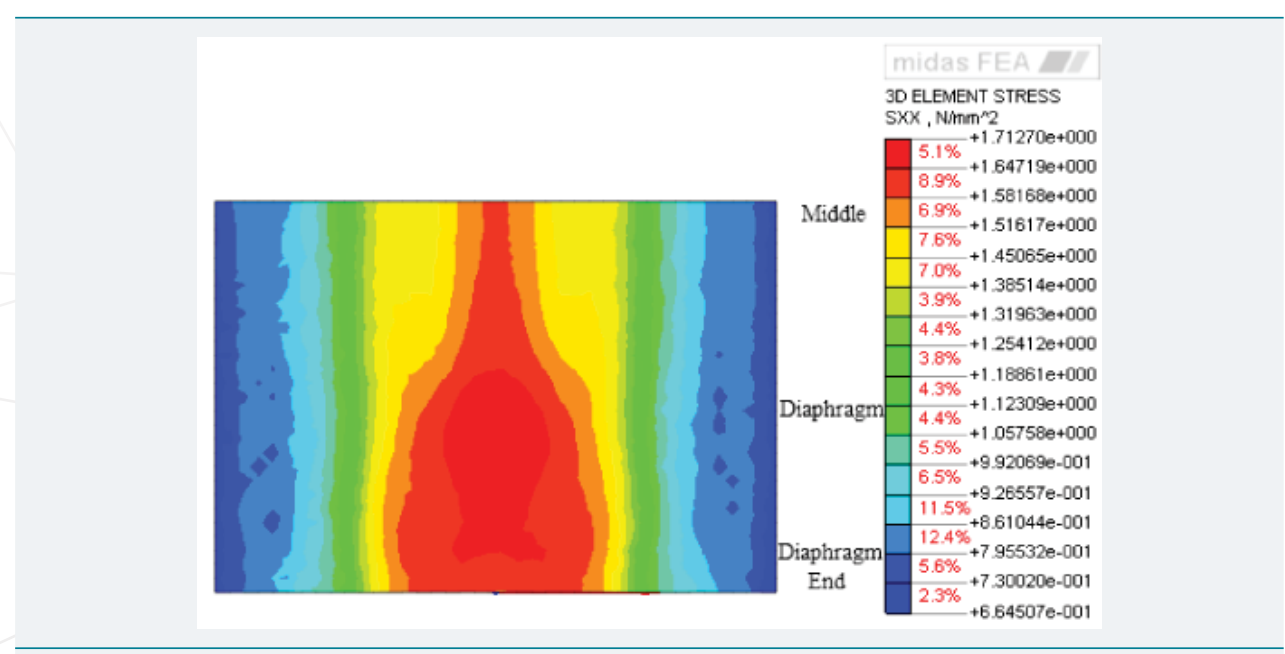

Figure 11: Transverse stress of roof under cooling

The figures 9-11, Box girder roof maximum transverse thermal stress occurs between two transverse diaphragm of the zero block, The maximum tensioncompression stress are $1.7 \mathrm{MPa}$ and $-3.4 \mathrm{MPa}$, this is caused by redundant constraints of box girder transverse frame, increased diaphragm plate making body redundant constraints increased, so that the transverse thermal stress is larger between the transverse diaphragm. 
The figures 10-12, the maximum longitudinal temperature stress of Box girder roof occurs in middle of zero block, The maximum tension-compression stress are 1.8MPa and $-3.7 \mathrm{MPa}$, reducing at transverse diaphragm position, it is because diaphragm plate interrupted the transmission of longitudinal temperature stress. And there is stress concentration phenomenon at the end of zero block.

The figures 13 and 14 in the diaphragm plate location, the scope of maximum principal tension-compression stress is reduced, and stress size has significantly decreased; but flange of zero block box girder end has a stress concentration phenomenon.

\section{Temperature stress distribution along the thickness of box girder roof}

The figures 15 and 16 the transverse distribution of temperature principal tensile stress along the box girder roof is uniform distribution. Temperature stress value between two webs is bigger than the two flanges; the stress value of temperature principal tensile stress reduced obviously with the increase of the thickness to top plate; the maximum stress value of top edge and $10 \mathrm{~cm}$ away from the top edge and $20 \mathrm{~cm}$ away from the top edge are 1.8MPa, 1.1MPa, 0.4MPa. Accordingly, Temperature stress is mainly distributed in box girder roof within $20 \mathrm{~cm}$, as the surface stress, surface reinforced configuration needs to be improved.
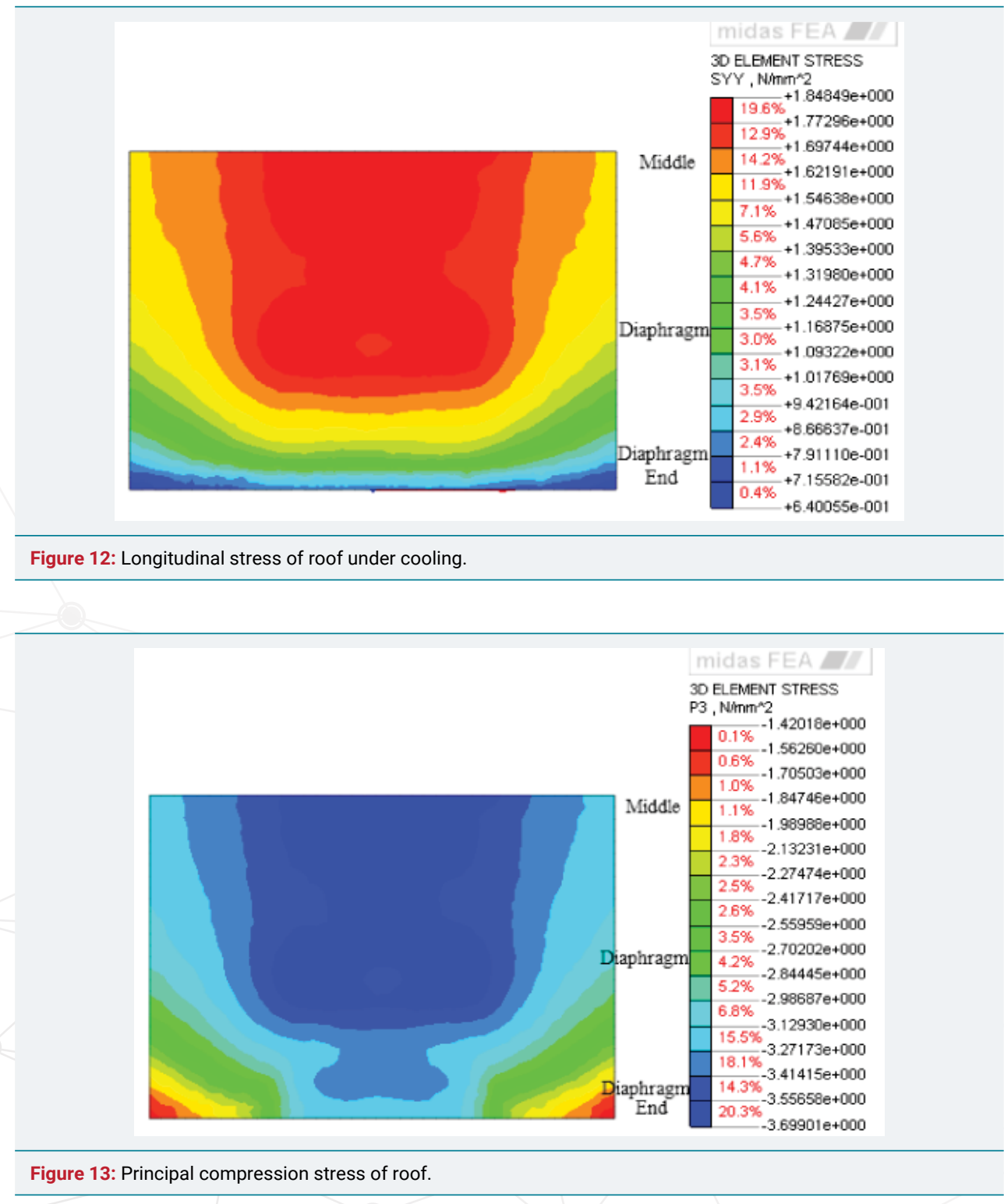


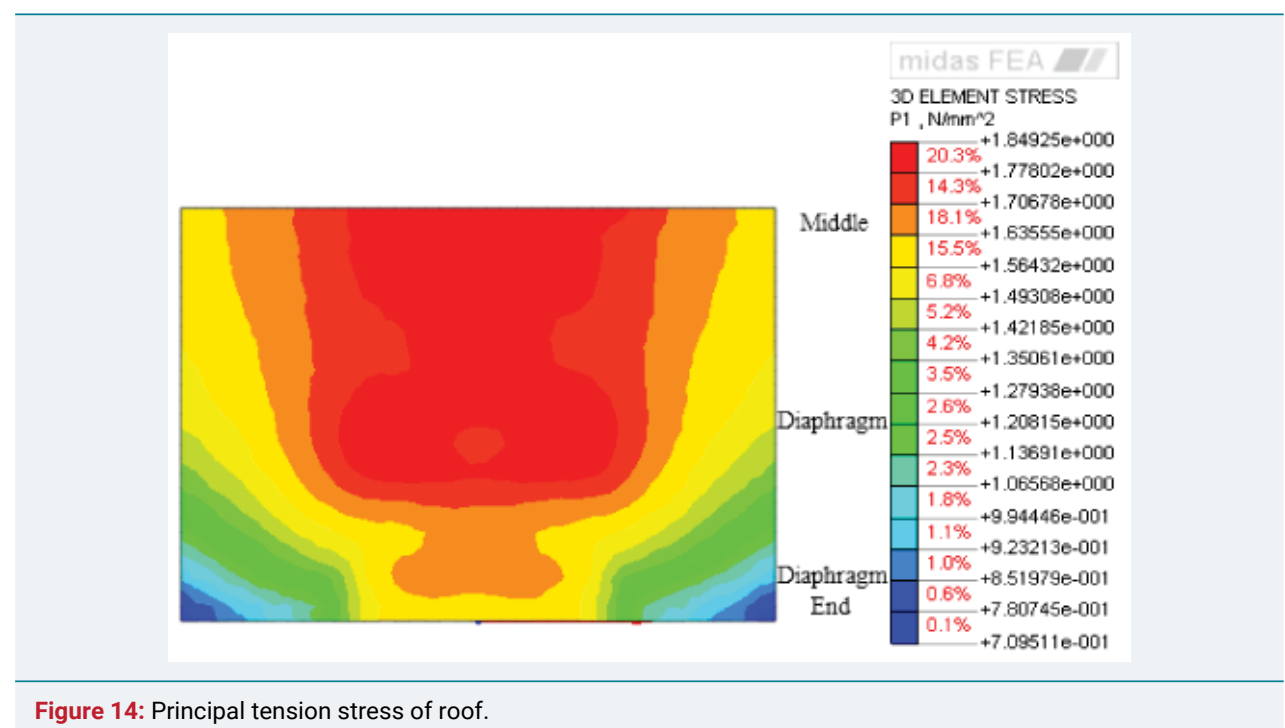

Figure 14: Principal tension stress of roof.

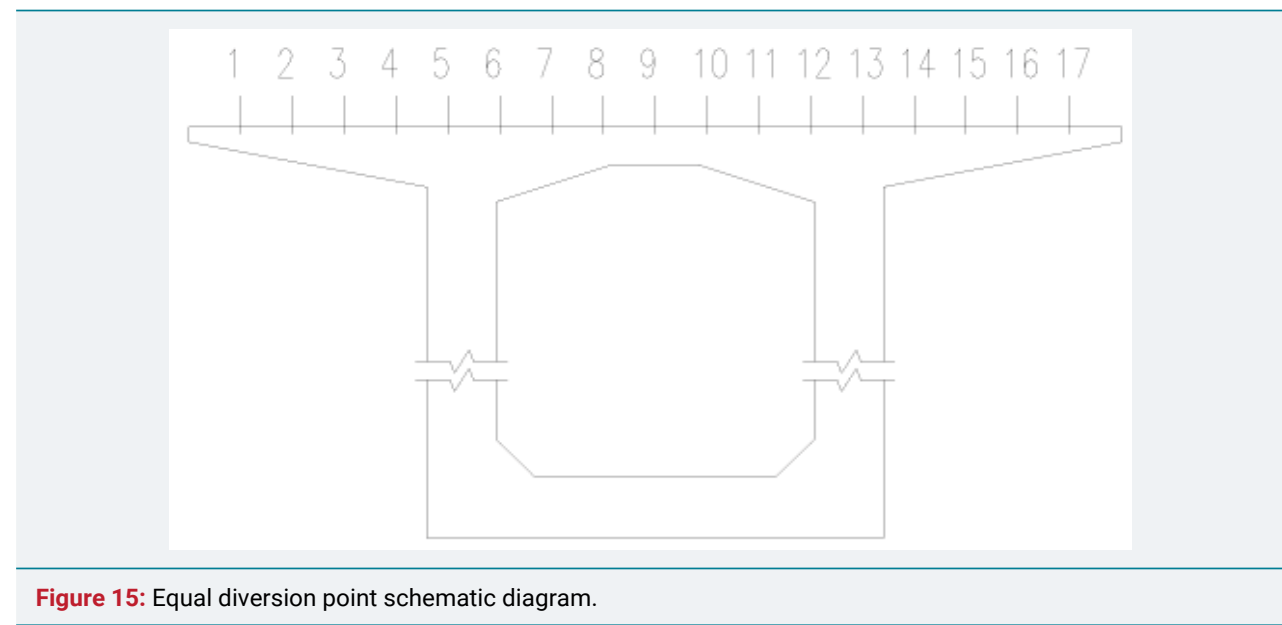

Temperature stress analysis under temperature gradient improved

The figures 17 and 18 under three working conditions, temperature principal tensile stress of the end of Zero block is smaller than the middle of Zero block. And as the improvement of the temperature field, the decrease amplitude of temperature stress is significant .Under three working conditions, in the middle of Zero block the maximum temperature principal tensile stress are $1.8 \mathrm{MPa}, 1.3 \mathrm{MPa}, 0.7 \mathrm{MPa}$, the end maximum temperature principal tensile stress are 1.6MPa, $1.1 \mathrm{MPa}, 0.4 \mathrm{MPa}$; The temperature stress improvement rate of middle and end of Zero block are about $61 \%$ and $75 \%$.

The figure 18, with the complicated structure of zero block, the two spacing of $2.4 \mathrm{~m}$ diaphragm plate and web plate form a closed box, these make Temperature stress complex, temperature stress between webs is great bigger than the flanges, and the shear lag effect is obvious.

\section{CONCLUSIONS}

In this article, through the simulation analysis method, using the finite element software Midas Civil and FEA, analyzed the temperature stress of continuous rigid frame bridge from the whole and the detail, as the conclusions follow:

(1) On the whole, under the temperature rise, cross section on the edge are all compressive stress, the lower edge of the section are all tensile stress, cooling is on the other hand. The temperature stress relationship of all the key section of the bridge is: 


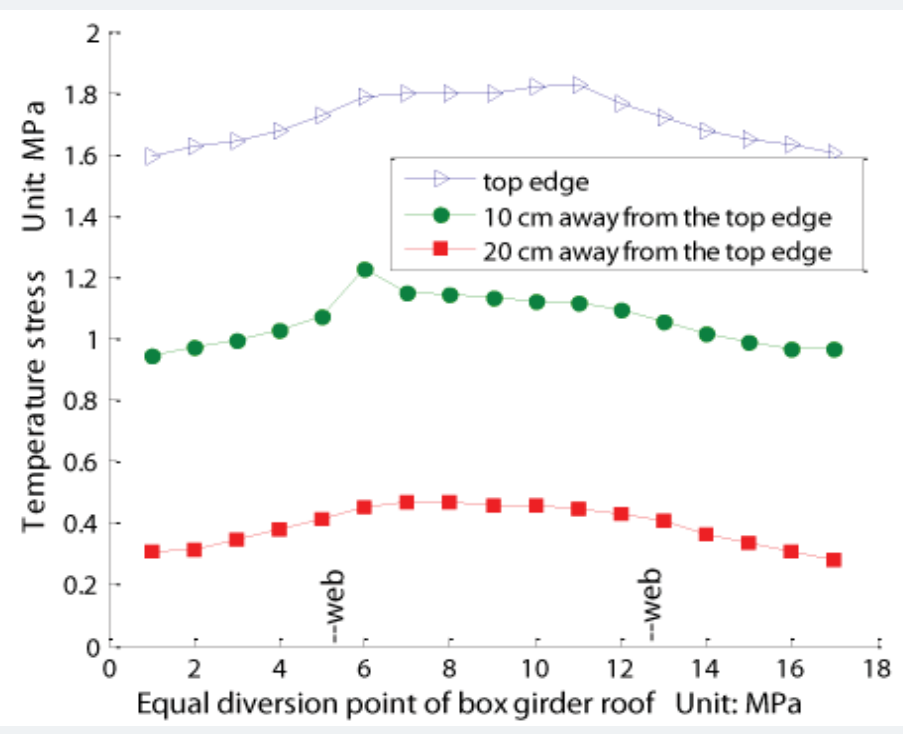

Figure 16: Principal tensile stress along roof.

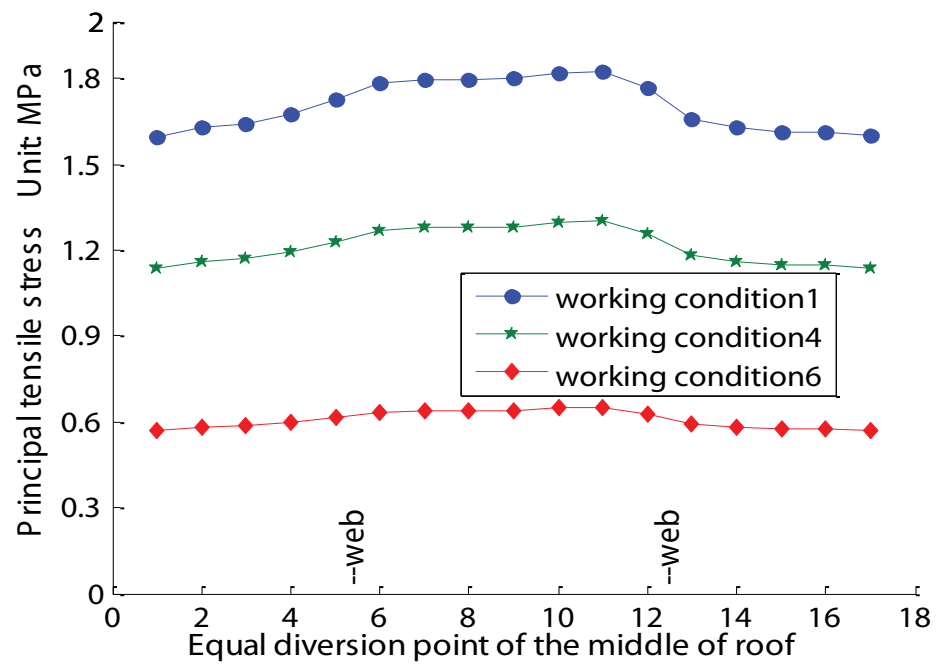

Figure 17: Middle of Zero block stress improvement.

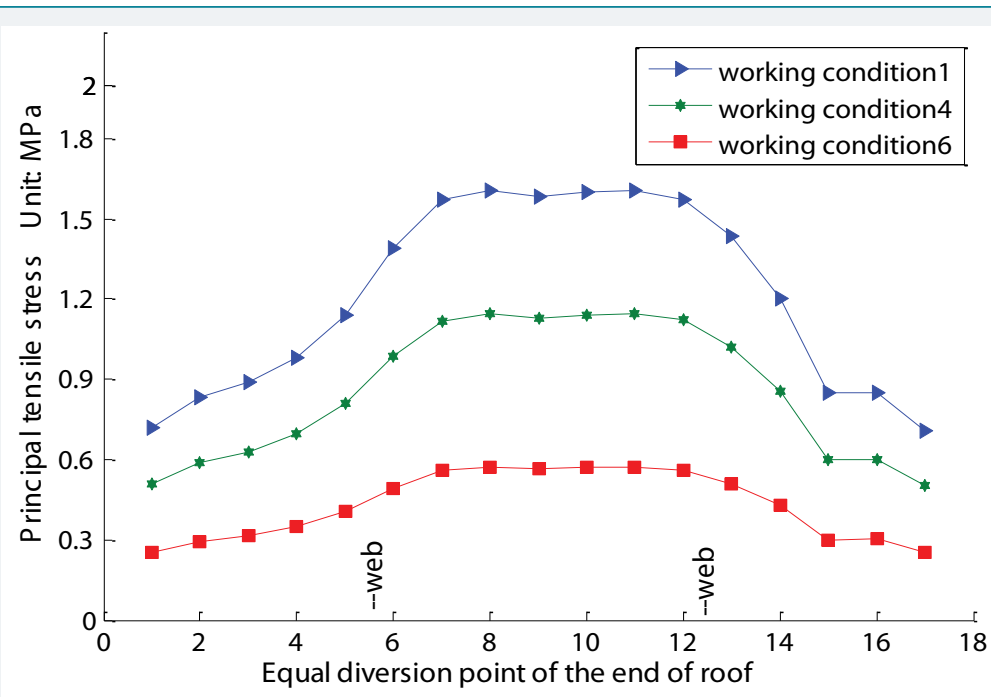

Figure 18: End of Zero block stress improvement. 
$1 / 2$ main span= root $>1 / 4$ side span $>1 / 4$ mid span $>$ side span. Upper and lower margin temperature stress of the box is linear relationship with improved temperature range.

(2) From the detail, redundant constraints of box girder transverse frame cause transverse temperature stress, the increase of the horizontal clapboard increase body redundant constraints, so that transverse temperature stress between the horizontal clapboard is larger; But the longitudinal temperature stress reduced because of stress is blocked in the horizontal clapboard.

(3) Temperature stress is mainly distributed in box girder roof within $20 \mathrm{~cm}$, as the surface stress, surface reinforced configuration needs to be improved.

(4) 9 degrees for improved temperature gradientamplitude, the central temperature stress of zero block decreases about $60 \%$, and the end of zero block decreases about $75 \%$.

This paper studied the improved amplitude of temperature stress under improvement of temperature gradient, but didn't consider the influence of material factors on temperature stress, such as elastic modulus, poisson ratio, thermal expansion coefficient and so on. These factors need to be studied furt.

\section{ACKNOWLEDGEMENT}

The research was partly supported by the National Science Foundation of China (Grant no.: E080505).

\section{REFERENCES}

1. Chen ZS, Zhou JT, Tse KT, Hu Gang, Li Yong, et al. Alignment control for a long span urban rail-transit cable-stayed bridge considering dynamic train loads. Science China Technological Sciences. 2016; 59: 1759-1770. Ref.: https://goo.gl/tBAXxD

2. Chen ZS, Zhang C, Wang X, Ma CM. Wind Tunnel Measurements for Flutter of a Long-Afterbody Bridge Deck. Sensors (Basel). 2017; 17: 335. Ref.: https://goo.gl/lft9Hr

3. Liu Xingfa. Thermal stress analysis of concrete structures. People's Communication Press. 1991.

4. Zhang Jianrong, Zhou Yuanqiang, Ling Jianping. Solar radiation affection on concrete box girder temperature effect. Journal of Tongji University Natural Science. 2009; 36: 1479-1484. Ref. https://goo.gl/23vQlv

5. PJ Barr, JF Stanton, MO Eberhard. Effects of Temperature Variations on Precast, Prestressed Concrete Bridge Girders. Journal of Bridge Engineering. 2005; 10: 186-194. Ref.: https://goo.gl/a6JCjv

6. Nie Liying, Liu Mingpo. Study on Transverse Temperature Effect in Webs of Concrete Box Beam Based on Measured Data. World Bridges. 2016; 44: 53-56.

7. Li Zhaoxiang. Study on temperature effect of long-span continuous rigid frame railway bridges in Tibetan Plateau. Journal of Lanzhou Jiaotong University. 2014; 1: 171-174. Ref.: https://goo.gl/nxgp1

8. Zeng Qingxiang, Han Dajian, Ma Haitao. Analysis of temperature effects on prestressed concrete box girder bridges. Journal of Central South University (Science and Technology). 2010; 41. Ref.: https://goo.gl/dllQCX

9. He Xiang, Fang Shisheng, Fang Fei. Study on vertical temperature gradient field. Journal of Hefe University of Technology (Natural Science). 2016; 2: 223-226.

10. JTG D62-2004. Code of Design for Reinforced and Prestressed Concrete Highway Bridges.

11. JTG D60-2004. General Specification for Highway Bridge and Culvert Design. 